\title{
Progression of asbestos effects: a prospective longitudinal study of chest radiographs and lung function
}

\author{
R N JONES, ${ }^{1}$ J E DIEM, ${ }^{2}$ JANET M HUGHES, ${ }^{13}$ YEHIA Y HAMMAD, ${ }^{14}$ \\ H W GLINDMEYER,' H WEILL'
}

From the Pulmonary Diseases Section, ${ }^{1}$ Department of Medicine, Tulane University School of Medicine, Tulane Computing Services, ${ }^{2}$ Department of Biostatistics and Epidemiology, ${ }^{3}$ and Department of Environmental Health Sciences, ${ }^{4}$ Tulane University School of Public Health and Tropical Medicine, New Orleans, Louisiana, USA

\begin{abstract}
From an original prospective cohort of 244 current and ex-workers in two asbestos cement plants, longitudinal radiographic data covering ten years were available for 165 and lung function data covering about six years for 150. Estimates of average and cumulative dust exposure were available for each participant, all men. Radiographic progression (onset or worsening) was assessed by comparing earliest and latest films side by side. Annual changes in lung function were computed by fitting regression lines to all the data points. Small opacities (ILO category $1 / 0$ or higher) were found in $16 \%$ of initial films, and progression of small opacities occurred in $13 \%$ of film pairs. Average and cumulative dust exposure were each significant determinants of the initial presence of small opacities, and were determinants of the progression of both parenchymal and pleural abnormalities. There was greater likelihood of progression if an abnormality was initially present, and a greater likelihood of progression in the plant that had systematic use of some crocidolite. Initial levels of lung function were related to smoking, exposure to dust, and initial radiographic status. Mean annual declines in lung function were modest (FVC $\left.-0.0171 / y, F E V_{1}-0.0201 / y\right)$ and were related to smoking but not exposure to dust, initial radiographic status, or radiographic progression. Both plants used mainly chrysotile asbestos and exposure levels declined severalfold after 1960. Our findings suggest a waning effect of the larger remote dust exposures on recent annual change in lung function. This accords with human and experimental pathology data showing the relatively low resistance of chrysotile fibres to chemical alteration and clearance.
\end{abstract}

\begin{abstract}
Asbestosis and asbestos induced pleural thickening and calcification share several characteristics. By definition, they are caused by exposures to asbestos (usually, occupational), and they are normally diagnosed with a chest radiograph. They each show exposure radiographic response relations, although they have different slopes and different prevalences. With the exception of organisation after asbestos pleural effusion, ${ }^{1}$ they have long latent periods between first exposure and detectable manifestations. Each is chronic and tends to progress, even after exposure has ceased. Since the late onsets and subsequent worsenings both reflect gradual advance of
\end{abstract}

Accepted 18 January 1988 tissue changes, the term progression is hereafter used to mean both onsets ("attacks") and worsenings.

Rates of radiographic progression may be determined from serial films and their functional concomitants from repeated lung function tests. Accumulated knowledge of the risk and course of progression is applied to prognosis, and this in turn influences both the medical approach to individuals and the societal response to such problems as compensation.

The purpose of this study was to learn the determinants and lung function effects of radiographic progression. The cohort reported here consisted of older men with individually estimated asbestos exposures, and was examined prospectively for longitudinal radiographic progression and change in lung function. 


\section{Study population and methods}

The subjects had participated in two previous studies. A brief review of each provides the context for the present methods and results.

CROSS SECTIONAL SURVEY, $1970^{23}$

In 1969 and 1970 cross sectional observations of exposures to dust and respiratory health in asbestos cement (AC) manufacturing workers were carried out in New Orleans. The participants were current and recently retired or laid off workers at two local AC products plants. The study population included 859 men with satisfactory pulmonary function tests, or $91 \%$ of those eligible. Dust exposure levels were estimated from existing air sampling data, supplemented by knowledge of production process and formulation changes, and by judgments of relative dustiness of outmoded processes by older workers. Measurements had been obtained with the midget impinger, yielding particle counts expressed in millions of particles per cubic foot of air (mppcf). Units of cumulative exposure were mppcf times years (mppcf-y). A questionnaire was used to ascertain symptoms and smoking history. Frontal and oblique chest radiographs were obtained, but only the frontal projection was classified according to the ILO U/C 1971 classification. ${ }^{4}$ Lung function tests included spirometry, lung volumes, single breath diffusing capacity, and expired volumes and oxygen uptakes at two levels of submaximal exercise.

LONGITUDINAL COHORT, 1970-6

In 1973 a cohort was constituted of men then available for examination who had been 44-59 at the time of the cross sectional study. There were 244 such men, with means for age $=51$, duration of exposure $=21 \cdot 3$ years, and average exposure $=12.8$ mppcf. In 1976, 204 were still under observation. Radiographic examinations and lung function testing were done over periods of 12-18 months, beginning in 1973 and in 1976. The radiographic observation period, by including the 1970 cross sectional study films, was about seven years. Because of changes in methodology the 1970 lung function measurements were not comparable with those made later, so the longitudinal lung function observations were from 1973 to 1976. Radiographic progression was counted if either of two independent observers scored the film pair (earliest and latest, viewed side by side in known order $)^{67}$ as showing definite or probable progression.

\section{PRESENT STUDY: LONGITUDINAL COHORT,} 1970-80

In the 1980 round of examinations 167 of the original 244 were examined. Satisfactory film pairs from the first and latest examinations were available for $16 \overline{\bar{E}}$ and serial spirometric data existed for 150 .

By the end of the 1980 round, some of the cohor who were still employed had accumulated as many as: 11 years of further dust exposure. More duss measurements also became available, some made i $\Phi$ the interval since 1970 and some earlier measurement discovered after the cross sectional study. Thes circumstances led to a revision of past exposur 8 estimates for most jobs and to an addition of intervad exposures to the cumulative dose estimates of those. who had continued to work in the plants into the 1970 s.

Radiographic examination and lung function test $\vec{\omega}$ ing were done as in the 1973 and 1976 rounds of the study. The film pairs (earliest and latest fronta radiographs of each man) were thoroughly shuffledf making sure that no pair members were near each other in the series. Three experienced readers, working independently and without knowledge of exposure classified the films according to the ILO $198 \bar{\theta}$ classification for the assessment of baseline status, and initial and final abnormality prevalences. ${ }^{8}$ The pair 8 were then reconstituted and read side by side for progression, still without exposure data. Baselin这 radiographic status for small opacities was taken as. the median of the readers' profusion scores, and fo50 presence of pleural thickening or calcification as क्षैe majority judgment. Each reader scored progression a seven point scale: definite, probable, and poss progression were respectively scored 1,2 , and $3 ; \hbar \bar{\hbar}$ change was scored 4; and possible, probable, an\& definite regression were respectively scored 5,6 , and $\mathrm{T}_{\varrho}$ Pairs were excluded if any reader thought that technical deficiencies made it impossible to assesड్ change. Separate progression judgments were made for pneumoconiotic small opacities, pleural thickene ing, and pleural calcification. A pair was counted as showing progression of an abnormality if its meas progression score was less than 3.

The distribution of exposures was examined to select scales for use in the subsequent analysesi Natural log transformation was found to produce symmetrical distribution of average exposure and square root transformation did the same fo cumulative exposures, so these transformed values were selected.

Baseline lung function was determined from the 1973 tests. Annual change in a lung function test for each subject was the slope of the least square? regression line fit to his test points in the period 1973 t $\Phi^{\circ}$ 1980. Mean annual change was the average of individual slopes.

Multiple logistic regression was used to examin relations between radiographic progression and the $\vec{e}^{+}$ following potential influencing variables: plant, race 
age at first film, smoking category at first film (current, ex-, never), pack-years, age at first exposure, time from first exposure to first film, duration of exposure, natural $\log (\mathrm{ln})$ of average exposure, square root (sq $\mathrm{rt}$ ) of cumulative exposure, and presence or absence of the several radiographic abnormalities on the initial film (for small opacities, dichotomised between categories $0 / 1$ and 1/0). Major emphasis was placed on describing relations between dust exposure variables and radiographic progression; other variables were treated as potential confounders or effect modifiers. Multiple linear regression was used to test potential determinants of baseline lung function and annual change in lung function, controlling for smoking. Inclusion criteria for annual change analysis were acceptable quality data from the 1980 round and at least one of the two preceding rounds. If three data points were available all were used to compute annual change.

\section{Results}

CROSS SECTIONAL SUR VEY, $1970^{23}$

Analysis of radiographic results showed that $32 \%$ had some relevant abnormality. Pneumoconiotic small opacities alone, of profusion grade $1 / 0$ or higher, were found in $8 \%$, pleural abnormalities alone were found in $15 \%$, and $9 \%$ had both. The prevalences of irregular, rounded, and both types of small opacities were significantly related to cumulative dust exposure. Statistically significant inverse relations were found between cumulative dust exposure and TLC, VC, FVC, $\mathrm{FEV}_{1}$, and $\mathrm{FEF}_{25-75}$. Significant dose response relations for each of these tests persisted when only subjects with normal radiographs were considered. In

Table 1 Comparison of "survivors" and "dropouts"

\begin{tabular}{|c|c|c|}
\hline & \multicolumn{2}{|c|}{ Observed through 1980} \\
\hline & Yes & No \\
\hline $\begin{array}{l}\text { No } \\
\text { Mean age (y) } \\
\text { Cigarette smokers (\%) } \\
\text { Chronic bronchitis (\%) }\end{array}$ & $\begin{array}{l}167 \\
50 \cdot 2 \\
74 \\
2\end{array}$ & $\begin{array}{l}77 \\
53 \cdot 3 \\
86 \\
8\end{array}$ \\
\hline $\begin{array}{l}\text { Exposure: } \\
\text { Mean duration (y) } \\
\text { Average level (mppcf) } \\
\text { Mean cumulative (mppcf-y) }\end{array}$ & $\begin{array}{r}21 \cdot 3 \\
6 \cdot 0 \\
138\end{array}$ & $\begin{array}{c}24 \cdot 1 \\
6 \cdot 2 \\
153\end{array}$ \\
\hline $\begin{array}{l}\text { ILO category: } \\
\text { Small opacities }>=1 / 0(\%) \\
\text { Pleural thickening }>=1(\%)\end{array}$ & $\begin{array}{l}16 \\
19\end{array}$ & $\begin{array}{l}18 \\
22\end{array}$ \\
\hline $\begin{array}{l}\text { Mean lung function in } 1973 \text {, } \\
\text { in \% predicted: } \\
\text { No } \\
\text { FVC } \\
\text { FEV }_{1} \\
\text { FEV }_{1} / \text { FVC } \\
\text { FEF }_{25} \cdot 75\end{array}$ & $\begin{array}{l}135 \\
90 \cdot 0 \\
88 \cdot 8 \\
77 \cdot 2 \\
77 \cdot 4\end{array}$ & $\begin{array}{rl} & 61 \\
* & 85 \cdot 5 \\
* & 81 \cdot 1 \\
* * & 73 \cdot 4 \\
* * 62 \cdot 9\end{array}$ \\
\hline
\end{tabular}

*p $<0.05 ; * * p<0.005$. subjects with small opacity profusion of category $2 / 1$ or higher, significantly lower mean TLC, VC, and DLCO values were observed, and these relations were more pronounced in those with irregular small opacities.

\section{LONGITUDINAL COHORT, 1970-6}

Progression of irregular small opacities $(n=17)$ was found to be related to both average and cumulative dust exposure. Progression of pleural thickening $(n=40)$ or calcification $(n=12)$ was related only to duration of exposure (and time since first exposure, which was highly correlated with duration). Higher cumulative dust exposure was associated with larger annual declines in FVC and FEV 1 (beyond smoking effects); and progression of irregular small opacities was associated with larger declines in those tests and in $\mathrm{FEF}_{25-75}$. Men showing progression of pleural thickening had larger declines in FVC and $\mathrm{FEV}_{1}$. Progression of calcification had no significant effect.

PRESENT STUDY: LONGITUDINAL COHORT, 197080

\section{Population}

The 167 men examined had a mean radiographic follow up of 9.75 years. Table 1 shows a comparison of those remaining and those lost to follow up. The "survivors" were on average three years younger and had $12 \%$ fewer smokers, a quarter the prevalence of chronic bronchitis, $10 \%$ lower mean cumulative exposure, and significantly better spirometric values. Of the 77 "dropouts" between 1973 and 1980, 29 were known dead, including ten of circulatory diseases, nine of cancers (including two bronchial and two oesophageal carcinomas, and one pleural mesothelioma), and two of asbestosis.

\section{Exposure}

The updating and revision of job exposure estimates changed the cumulative exposure profile of the whole cohort and the 1980 participants. It also resulted in changes in the rank order of individuals, according to particular jobs held and whether exposures continued after 1970. Table 2 shows the different cumulative exposure ranges for the four quartiles of the whole cohort, and the prevalences of initial films showing small opacities (ILO category $1 / 0$ or greater) in these exposure ranges for the original and 1980 groups. Both the original and the revised estimates produced significant dose response relations. The revision resulted in clear differences between prevalence rates of the first and second, and of the third and fourth, quartiles, whereas the older estimates had produced clear differences among the first three quartiles but not between the third and fourth. The changes in rank 
Table 2 Prevalences (per cent) of small opacities* by original and revised exposure estimates

\begin{tabular}{lcc}
\hline $\begin{array}{l}\text { Cumulative } \\
\text { exposure }\end{array}$ & $\begin{array}{l}\text { Original cohort } \\
(n=244)\end{array}$ & $\begin{array}{l}\text { Present group } \\
(n=165)\end{array}$ \\
\hline Original estimate: & & \\
$<110$ & $4 \cdot 8$ & $6 \cdot 1$ \\
$110-264$ & $15 \cdot 5$ & $10 \cdot 8$ \\
$265-439$ & $23 \cdot 3$ & $26 \cdot 2$ \\
$\geqslant 440$ & $24 \cdot 6$ & $26 \cdot 3$ \\
Revised estimate: & & \\
$<75$ & $8 \cdot 1$ & $6 \cdot 5$ \\
$75-127$ & $16 \cdot 7$ & $18 \cdot 2$ \\
$128-179$ & $18 \cdot 2$ & $19 \cdot 1$ \\
$\geqslant 180$ & $27 \cdot 8$ & $28 \cdot 1$ \\
\hline
\end{tabular}

*ILO profusion category $1 / 0$ or greater.

†In million particles per cubic foot, times years (mppcf-y) the ranges dividing the original cohort into quartiles.

order of individuals are reflected in the rates of movement into different exposure quartiles. An analysis was performed in those subjects whose original films showed small opacities. Thirty nine per cent stayed in the same quartile and $\mathbf{4 0 \%}$ moved into an adjacent quartile, upward and downward movements occurring with equal frequency.

Of the 165 men with radiographic follow up until 1981, 96 had been employed in plant 1 and 69 in plant 2. Mean cumulative exposures by plant were virtually identical, 140.8 and 139.4 mppcf-y.

\section{Radiography}

Satisfactory film pairs existed for 165 of the 167 participants. Table 3 shows the initial and final distributions by category of radiographic abnormality, derived from the random order readings. These provide some indication of mean progression but do not reflect instances of progression within the same ILO category of small opacity profusion or pleural abnormality extent. Table 4 shows the results of logistic regression analysis for first order relations of potential explanatory variables with abnormalities
Jones, Diem, Hughes, Hammad, Glindmeyer, Weitt

Table 4 First order relations for initial radiographic abnormality: $p$ values from estimated logistic regression coefficients

\begin{tabular}{|c|c|c|}
\hline Variable & $\begin{array}{l}\text { Small } \\
\text { opacities }\end{array}$ & $\begin{array}{l}\text { Pleural } \\
\text { thickening }\end{array}$ \\
\hline $\begin{array}{l}\text { Plant* } \\
\text { Race* } \\
\text { Age (1970) } \\
\text { Age at first exposure } \\
\text { Smoking category } \\
\text { Pack-years } \\
\text { Time since first exposure } \\
\text { Duration of exposure } \\
\text { Average exposure (natural log) } \ddagger \\
\text { Cumulative exposure (square root) } \ddagger\end{array}$ & $\begin{array}{l}0.0167 \\
\text { NSt } \\
\text { NS } \\
0.005 \\
\text { NS } \\
0.025 \\
0.016 \\
0.014 \\
0.038 \\
0.038\end{array}$ & $\begin{array}{l}0.063 \\
0.037 \\
0.058 \\
\text { NS } \\
\text { NS } \\
0.002 \\
0.068 \\
0.044 \\
\text { NS } \\
\text { NS }\end{array}$ \\
\hline $\begin{array}{l}\text { p values for two tailed test. } \\
+ \text { NS = Not statistically significant. } \\
\ddagger \quad \text { Transformed exposure variables. }\end{array}$ & & \\
\hline
\end{tabular}

on the initial film. There were higher prevalences dip lung and pleural abnormality at one plant (plant 2) More pleural abnormalities were found in whites? There was an inverse relation between age at first exposure and risk of having small opacities. Smoking category was not significant, but pack-years were significant both for small opacities and pleurat thickening. Time since first exposure was significant for small opacities but only marginally significant fo $\overrightarrow{0}$ pleural thickening. Small opacities and pleural thigke्ठ ening were each related to duration of exposure. Snght opacities, but not pleural thickening, were relate both average and cumulative dust exposure (t transformed values).

The remaining analyses for radiographic progreso sion use the summary scoring of each film pair fror? readings done side by side and in correct tempora $\vec{\Phi}$ order, as described above. Table 5 shows numbers of progressors for separate and inclusive categories of radiographic abnormality. Fifty one of $165(31 \%)$ showed progression of at least one abnormalit $\$$ (parenchymal small opacities, or pleural thickening $\mathrm{OW}^{\mathrm{B}}$ pleural calcification). Twenty two (13\%) showed

Table 3 Results of random order readings

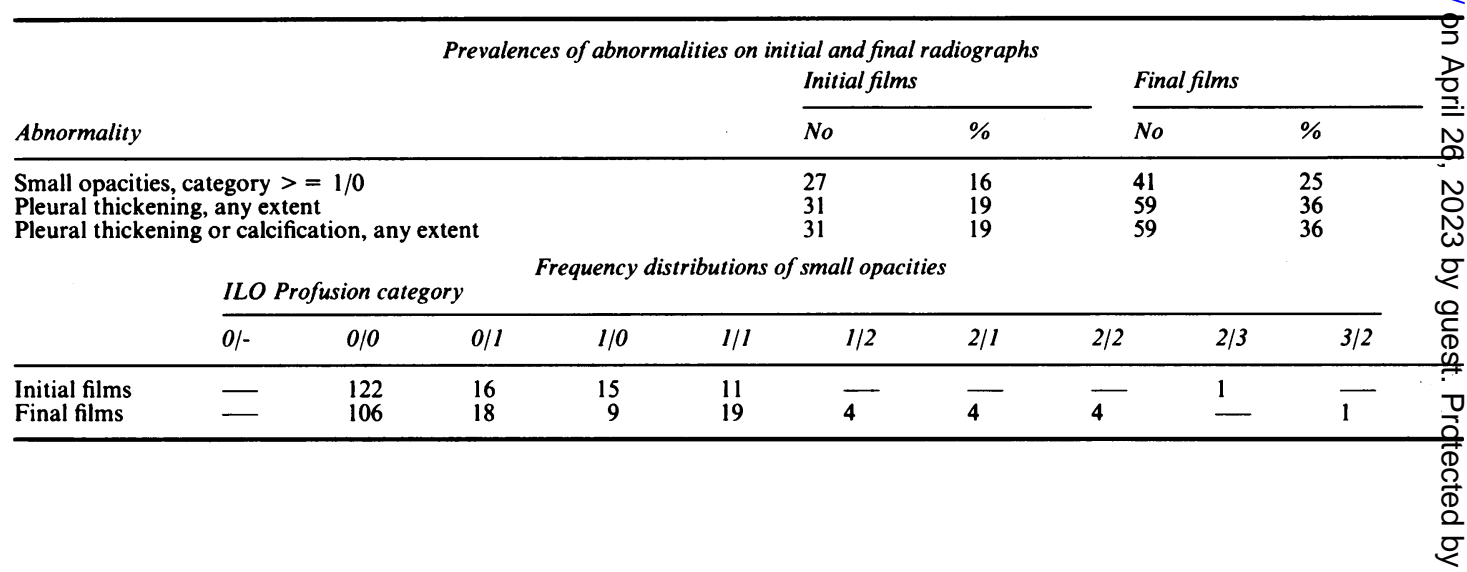


progression of small opacities, 13 of those also showing progression of pleural abnormality.

As a preliminary to analysis for determinants of progression, first order relations with potential explanatory variables were examined. For progression of small opacities, statistically significant $(\mathrm{p}<=$ 0.05 ) relations were observed for plant, transformed average and cumulative exposures, and presence of small opacities on initial film; and a marginally significant $(0.05<p<0.10)$ relation was observed for pack-years of cigarette smoking. For progression of pleural abnormality, there were significant first order relations to transformed average and cumulative exposures, and to presence of pleural abnormality on initial film; and there were marginally significant relations to plant, pack-years, current versus never cigarette smoking, duration of exposure, and time from first exposure to first film. Probabilities of small opacity or pleural progression were greater in the same plant, plant 2. Concerning duration of exposure and time from first exposure to 1970, these variables are so highly correlated $(r=0.98)$ as to be inextricably confounded.

The determinants of progression of parenchymal and pleural abnormality were identified through multivariate analysis. Parallel analyses were carried out by building separate models around the other significant variables and cumulative exposure, then average exposure. The cumulative exposure models were also tested by substitution of combinations of duration and average exposure measures to test for effects of these components. In the end identical results were provided by the average and cumulative exposure models, and both variables are equally explanatory of progression. The cause of this is found in the relatively narrow range of exposure durations produced by the inclusion criterion of age 44 to 59 in 1970 . Most of these men had been hired in the building boom after the second world war, and there had been relative stability in the workforce through the subsequent 20 years. This feature of the cohort may explain the failure to detect independent effects of duration of exposure and time since first exposure on progression-especially progression of pleural abnormality,

Table 5 Numbers showing radiographic progression, from side by side readings of 165 film pairs

\begin{tabular}{lll}
\hline & \multicolumn{2}{l}{ Progression } \\
\cline { 2 - 3 } Abnormality & No & Per cent \\
\hline Small opacities & 22 & $(13)$ \\
Pleural thickening & 38 & $(23)$ \\
Pleural calcification & 7 & $(4)$ \\
Pleural thickening or calcification & 42 & $(25)$ \\
$\begin{array}{l}\text { Small opacities and pleural thickening } \\
\text { or calcification }\end{array}$ & 13 & $(8)$ \\
Any abnormality & 51 & $(31)$ \\
\hline
\end{tabular}

Table 6 Multivariate analyses for radiographic progression

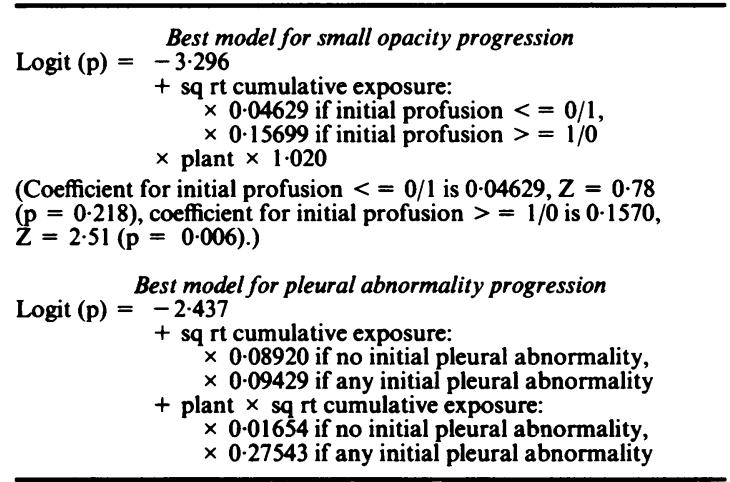

for which there is evidence from other studies of the importance of time.

Table 6 shows the results of multivariate analysis for determinants of progression of small opacities. Of the variables found to have significant or marginal first order relations to progression, smoking proved to have no significance after control for other variables. The significant variables were dust exposure in interaction with initial radiographic status, and plant. There was a significant dust exposure progression relation for those with initial parenchymal abnormality but not for those without. There was a higher probability of progression in plant 2 workers.

A model with four potential exposure progression relations was also fitted to the data, one for each combination of initial film abnormality (present or absent) and plant ( 1 or 2 ), all having the same value when cumulative exposure $=0$. There was no significant difference in exposure progression relations between plants for either category of initial profusion, meaning that the coefficients of exposure in the models were the same for the two plants. The coefficient of plant, however, was statistically significant, indicating the higher probability of progression in plant 2 workers. From this and the simpler model, it appears that plant differences are manifested by a difference in position on the logit scale rather than a difference in exposure coefficients.

Table 6 also shows the analysis for progression of pleural abnormality. Smoking (pack-years) was not a significant determinant of pleural progression. The significant determinants were dust exposure in interaction with initial pleural radiographic abnormality, and plant in interaction with initial pleural abnormality. The model incorporating combinations of plant and presence/absence of initial pleural abnormality gave different results from the corresponding one for small opacity progression. Three combinations had significant relations and the fourth was marginally significant. In those with initial pleural abnormality 
Table 7 Initial lung function (per cent of predicted values): coefficients* in multiple linear regression analysis

\begin{tabular}{|c|c|c|c|c|c|c|}
\hline \multirow[b]{2}{*}{ Variable } & \multicolumn{6}{|l|}{ Test } \\
\hline & $F V C$ & $F E V_{1}$ & $F E F_{25-75}$ & $T L C$ & $R V$ & $D L$ \\
\hline $\begin{array}{l}\text { Smoking: } \\
\text { Current } v \text { never } \\
\text { Ex- } v \text { never } \\
\text { Small opacities, profusion } 1 / 0 \text { or more } \\
\text { Pleural thickening or calcification } \\
\text { Average exposure (mppcf) } \\
\text { Plant } 2\end{array}$ & $\begin{array}{l}-11.3 \\
-9.5 \\
-0.5 \\
4.6\end{array}$ & $\begin{array}{l}-9.0 \\
-7.9 \\
-10.1 \\
-10.2 \\
-0.7\end{array}$ & $\begin{array}{l}-26.6 \\
-18.7 \\
-13.8 \\
-0.9\end{array}$ & $\begin{array}{l}6.1 \\
0.6\end{array}$ & $\begin{array}{l}6.1 \\
0.6 \\
-9.4 \\
-7.7\end{array}$ & $\begin{array}{l}-17 \cdot 5 \\
-10 \cdot 5 \\
9 \cdot 7 \\
7 \cdot 2\end{array}$ \\
\hline
\end{tabular}

there were significantly different exposure coefficients (higher for plant 2), indicating different slopes for the exposure response relations in the two plants.

\section{Lung function}

There were 150 men with satisfactory radiographs who also met pulmonary function inclusion criteria. Of these, 133 had satisfactory spirometry in 1973, the initial lung function data point. Mean initial values for spirometric tests, in per cent predicted, are shown in table 1. Table 7 shows the results of multiple linear regression analysis for determinants of initial level of lung function. Smoking had significant influence on all tests except FVC. After control for smoking effects, initial radiographic status (parenchymal or pleural) had expected effects on several spirometric tests and residual volume. After control for the preceding, average exposure had significant effects on FVC, $\mathrm{FEV}_{1}$, and $\mathrm{FEF}_{25-75}$. Finally, plant 2 was associated with higher DLCO and higher FVC, observations that are not explained by the known determinants of lung function and so probably represent preexisting differences between the workers in the two plants.

Table 8 shows the mean annual changes for the several lung function tests. These rates of change are quite modest-for example, $F V C=-0.0171 / y$, $\mathrm{FEV}_{1}=-0.020 \mathrm{l} / \mathrm{y}$. Initial test level had a significant effect on subsequent rate of test change for most tests of'lung function. There are two approaches to the analysis. One is to examine the other variables for significance beyond the effect of initial test level. This $\overrightarrow{\vec{\omega}}$ could obscure effects of past exposures on current $\vec{\sigma}^{\circ}$ rates of change because initial test levels were in parto determined by exposure (table 7). The other is to $\frac{\mathbb{}}{3}$ ignore initial test level, which avoids inadvertent adjustment for effects of past exposures. Both methods ${ }_{\mathrm{N}}^{\circ}$ were tried, and gave the same results in identifying 0 significant determinants of annual change.

Table 8 shows the results of multiple linear regres- $\stackrel{\circ}{-}$ sion analysis, testing for significant effects of other $\vec{T}$ potential determinants while ignoring initial levels of $\Phi$ lung function. The most notable result is the failure to find significant effects of any (continuous) exposure variable, or of initial radiographic status or progression, on any lung function test. The apparent $\oplus_{\infty}$ exception, a putative effect of progression of pleural.e thickening on TLC and RV, is in reality an isolated effect on RV (the progressors' mean RV declining 64 $\mathrm{ml} / \mathrm{y}$ faster and their mean TLC $36 \mathrm{ml} / \mathrm{y}$ faster than the non-progressors). There is no significant effect of $\cong$ pleural progression on FVC, a finding which casts $\stackrel{\complement}{\unrhd}$ serious doubt on the biological significance of the $\overrightarrow{\vec{P}}$ observed relation.

As expected, smoking was a significant determinant of declines in spirometric tests and increases in lungo volumes, its lack of statistically significant effect on $\mathrm{FEF}_{25-75}$ probably reflecting the greater variability in $\mathbb{\triangle}$ that test. Plant was associated with larger declines in:both spirometric tests and lung volumes. No 3 . explanatory variable was related to decline of $\mathrm{DLCO}_{\circ}$ or DLCO/alveolar volume.

Table 8 Rates of annual change in lung function

\begin{tabular}{|c|c|c|c|c|c|c|}
\hline \multirow[b]{2}{*}{ Variable } & \multicolumn{6}{|l|}{ Test } \\
\hline & $F V C$ & $F E V_{1}$ & $F E F_{25} 75$ & $T L C$ & $R V$ & $D L$ \\
\hline $\begin{array}{l}\text { No } \\
\text { Mean* } \\
\text { STD dev } \\
\text { Yariable. }\end{array}$ & $\begin{array}{l}150 \\
-0.017 \\
0.053\end{array}$ & $\begin{array}{l}150 \\
-0 \cdot 020 \\
0.041\end{array}$ & $\begin{array}{l}150 \\
-0.052 \\
0.097\end{array}$ & $\begin{array}{l}149 \\
0 \cdot 032 \\
0 \cdot 081\end{array}$ & $\begin{array}{l}149 \\
0 \cdot 062 \\
0 \cdot 071\end{array}$ & $\begin{array}{l}143 \\
0 \cdot 120 \\
0.631\end{array}$ \\
\hline $\begin{array}{l}\text { Variable: } \\
\text { Plant } 2 \\
\text { Progression of pleural thickening or calcification }\end{array}$ & $\begin{array}{l}-0.023 \\
-0.026\end{array}$ & $\begin{array}{r}-0.017 \\
-0.014\end{array}$ & & $\begin{array}{l}0.023 \\
-0.062 \\
-0.036\end{array}$ & $\begin{array}{l}0.038 \\
-0.035 \\
-0.034\end{array}$ & \\
\hline \multicolumn{7}{|c|}{ *Units FVC, FEV, TLC, RV: 1/y FEF ${ }_{25-75}: 1 / \mathrm{s} / \mathrm{y}$ DL: $\mathrm{mL} / \mathrm{min} / \mathrm{mm} \mathrm{Hg} / \mathrm{y}$. } \\
\hline
\end{tabular}




\section{Discussion}

The radiographic findings in this study are in general agreement with those of other population based studies of the course of asbestos related fibrotic conditions. ${ }^{9-15}$ Both lung and pleural abnormalities are slowly progressive and are usually relatable to intensity and duration of past exposures. The exposure relations differ between asbestosis and the pleural abnormalities for both prevalence and progression. The results of cross sectional studies showing higher prevalences of pleural than lung abnormalities ${ }^{16-18}$ support the conclusion that pleural abnormalities develop at lower cumulative asbestos exposures.

There are contradictory reports on the significance of smoking on radiographic findings in asbestos exposed groups. ${ }^{13-15171920}$ The present study shows positive relations between pack-years and the likelihoods of having lung and pleural abnormalities on the initial film but no significant effect of smoking on progression.

There was no significant interaction between exposure to asbestos and age or race on the prevalence or progression of radiographic abnormalities. The higher prevalences of lung and pleural abnormality at one plant (plant 2) may reflect unmeasured differences in exposure levels. There was, however, a systematic use of crocidolite in the pipe production area of plant 2 , although chrysotile was the primary fibre in both plants. In the dose progression relations for small opacities plant differences were in the origins on the logit scale not in the exposure coefficients, suggesting a systematic difference in estimating past exposure levels. For progression of pleural abnormalities, however, both the coefficients and origins differed, a finding that is more supportive of the possibility of different biological potency of dusts in the two plants. Because $85 \%$ of the plant 2 participants had been employed for at least some time in the pipe area, it was not possible to perform a separate analysis for fibre type effect.

The more remarkable findings come from the longitudinal assessment of lung function. The observed annual declines are modest and are unrelated to exposure variables. And although radiographic progression continues to occur, recent annual change in lung function is not related to the initial or subsequent radiographic findings. In this group of long term asbestos cement manufacturing workers the substantially higher past exposures to dust seem to have exerted their adverse effects on lung function in the past, before the start of the longitudinal study. The adverse functional effects of past exposure were clearly shown in the 1970 cross sectional survey of the large population from which the present cohort was drawn.

Because both exposure and radiographic progres- sion were found to have effects on lung function annual change in the 1970-6 follow up of this cohort, the discordance with current results might arise from attrition. Nevertheless, although the number followed up for radiographic change decreased from 195 to 165 , the number with two satisfactory spirometric tests decreased only from 151 to 150 (a result of having three, instead of two, opportunities to produce two satisfactory tests). Nor did the revision and updating of exposure estimates obscure the relations between exposure and either radiographic prevalences or risks of progression. The lengthening period of radiographic follow up, however, resulted in higher percentages of progressors. Although the risk of progression is significantly related to presence of the abnormality on the initial film, increasing duration of follow up must necessarily add instances of progression from normal to abnormal-that is, "attacks"-and between low levels of abnormality, particularly low categories of small opacities. There is a recognised effect of smoking on the prevalence of irregular small opacities in populations with and without exposures to asbestos. ${ }^{21}$ Since smoking is not a cause of high grades of pulmonary fibrosis, its potential for producing radiographic confounding is likely to be greatest at low profusion levels. Multivariate analysis involves controlling for smoking, then testing for effects of exposure or radiographic status per se on the residual variability in lung function. If the initial group of progressors is increased by the addition of those whose radiographs reflect mainly smoking, the expected result would be a decline in the power to detect lung function influences of the other variables.

These results may also reflect the biological behaviour of large chrysotile asbestos tissue burdens acquired in the distant past. Exposure levels in these plants have declined since the 1940 s and $1950 \mathrm{~s},{ }^{22}$ when the cohort acquired most of its cumulative exposure. If retained fibres were cleared only to a slight extent, and kept their fibrogenic potency, their effects on lung function should be found in both the initial cross sectional measurements and throughout the longitudinal follow up. The contrary finding suggests substantial long term clearance, or loss of potency, or both. Support for both mechanisms is found in reports on experimental asbestosis, showing that chrysotile fibres are chemically altered ${ }^{2324}$ and cleared more rapidly than amphibole fibres, even within the relatively short lifetimes of laboratory rodents. Still more support comes from postmortem studies of chrysotile miners ${ }^{25}$ and asbestos cement manufacturing workers, ${ }^{26}$ whose lungs eventually contain predominantly amphibole fibres, despite occupational exposures mainly to chrysotile. Thus the fibrogenic effects of a dose of chrysotile obtained mostly between 
40 and 20 years ago may now be largely spent. If this is so each succeeding year should show a reduction in the abnormal rates of decline attributable to exposure, which had produced the initial significant cross sectional relations between lung function level and both cumulative exposure and radiographic status. The results of the present study do not directly show changes in the annual rates of decline, but are consistent with slowing of these rates.

Regardless of the operative mechanisms, these results provide useful new information on the prognosis of asbestosis, as it is currently being diagnosed. The disorder, at low levels of radiographic abnormality, has a low likelihood of both radiographic and functional worsening in a ten year period.

Unfortunately, there are no closely comparable data on progression of asbestosis. Siracusa et al reported larger seven year declines in FVC and FEV, in 65 asbestos cement workers than in 30 controls exposed to polyvinyl chloride. ${ }^{27}$ An abnormally large mean rate of annual decline was found in those workers exposed to asbestos for longer than 15 years. No radiographic data were given and the two rounds of the study had been conducted by different teams of investigators. Ohlson et al reported a four year, two point study of 75 former asbestos cement workers, beginning when exposure ended because the plant closed. ${ }^{28}$ None of the subjects had or subsequently developed asbestosis. By comparison with 56 workers from other industries, the subjects had larger annual declines in FVC and $\mathrm{FEV}_{1}$, and there was a significant trend of increasing decline in FEV , with higher fibre exposure category. The magnitude of declines must be questioned, however, because of changes in spirometers and calibration during the study, and because of implausibly high mean declines of the controls.

Older studies have included subjects with the various radiographic abnormalities, but were retrospective,,$^{1012}$ or used disability claimants. ${ }^{2930}$ As exposure to asbestos continues to decline, retrospective cohort studies will be even less applicable to current experience. And as diagnosis continues to encompass minimally affected individuals, recently diagnosed asbestosis will less and less resemble the disease severity shown in past series of patients or disability claimants.

Whereas the lung function rates of annual change observed in this cohort would not be expected from a reading of reports, the reasons probably lie in both the declining effects of remote exposure to asbestos and in the study design. The prospective and exposure defined characteristics of the study minimise the depiction of past examples of the conditions to which retrospective cohorts are subject and avoid entirely the clinical bias of patient or compensation based

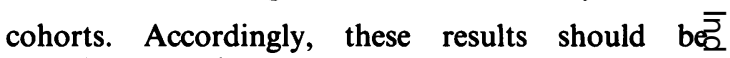
considered in formulating prognoses in currentlyz diagnosed cases of asbestos related fibrosis-unti $\mathbb{Z}$ future studies of this type expand and refine our: understanding of progression.

Supported by the Institute of Occupational and Environmental Health, and by Specialized Center of Research (SCOR) Grant HL-15092 from the Nationa $\vec{b}$ Heart, Lung and Blood Institute.

Requests for reprints to: Robert N Jones, MD, Tulane $\vec{P}$ University School of Medicine, Department of Medicine, Pulmonary Diseases Section, 1700 Perdidow Street, New Orleans, Louisiana 70112.

\section{References}

1 Gaensler EA, Kaplan AI. Asbestos pleural effusion. Ann Intern Med 1971;74:178-91

2 Weill $\mathrm{H}$, Waggenspack C, Bailey W, Ziskind M, Rossiter Co Radiographic and physiologic patterns among workers engaged in manufacture of asbestos cement products. $J$ Occup Med 1973;15:248-52.

3 Weill H, Ziskind MM, Waggenspack C, Rossiter CE. Lung function consequences of dust exposure in asbestos cemen manufacturing plants. Arch Environ Health 1975;30:88-97.

4 International Labour Office. Guidelines for use of the ILO/UC international classification of radiographs of pneumoconiosesco Geneva: ILO, 1971. (Occupational safety and health series $1981 \stackrel{0}{\circ}$ No 22.)

5 Jones RN, Diem JE, Glindmeyer H, Weill H, Gilson 平号 Progression of asbestos radiographic abnormalities: relationn ships to estimates of dust exposure and annual decline in ling function. In: Wagner JC, ed. Biological effects of mineral fibres Lyon: International Agency for Research on Cancer, 1980 음 537-43. (IARC sci publ No 30.)

6 Liddell FDK, Morgan WKC. Methods of assessing serial films of the pneumoconioses: a review. J Soc Occup Med 1978;28:6-15.

7 McMillan GHG, Rossiter CE, Deacon R. Comparison of independent randomised reading of radiographs with direc progression scoring for assessing change in asbestos-relateco pulmonary and pleural lesions. Br J Ind Med 1982;39:60-1.

8 International Labour Office. Guidelines for use of the ILO international classification of radiographs of pneumoconioses $\frac{}{3}$ Geneva: ILO, 1980. (Occupational safety and health series No 22 (rev).)

9 Liddell D, Eyssen G, Thomas D, McDonald C. Radiologica changes over 20 years in relation to chrysotile exposure in Quebec. In: Walton WH, ed. Inhaled particles IV. Oxford Pergamon Press, 1977:799-813.

10 Becklake MR, Liddell FDK, Manfreda J, McDonald JC? Radiological changes after withdrawal from asbestos exposure $D$ Br J Ind Med 1979;36:23-8.

11 Becklake MR, Thomas D, Liddell FDK, McDonald JC. Follow up respiratory measurements in Quebec chrysotile asbestos miners and millers. Scand J Work Environ Health 1982;8(supp/ 1):105-10.

12 Cookson W, De Klerk N, Musk AW, Glancy JJ, Armstrong BN Hobbs M. The natural history of asbestosis in forme crocidolite workers of Wittenoom Gorge. Am Rev Respir Dis 1986;133:994-8.

13 McMillan GHG, Rossiter CE. Development of radiological ancक्क clinical evidence of parenchymal fibrosis in men with nons malignant asbestos-related pleural lesions. $\mathrm{Br} J$ Ind $\mathrm{Med}_{0}$ 1982;39:54-9. 
14 Rubino GF, Newhouse M, Murray R, Scansetti G, Piolatto G, Aresini G. Radiologic changes after cessation of exposure among chrysotile asbestos miners in Italy. Ann NY Acad Sci 1979;330:157-61.

15 McMillan GHG, Sheers G, Pethybridge R. A radiological followup study of the effect of asbestos in dockyard workers at Devonport. Journal of the Royal Naval Medical Service 1978;64:88-103.

16 Jones RN, Diem JE, Ziskind MM, Rodriguez M, Weill H. Radiographic evidence of asbestos effects in American marine engineers. J Occup Med 1984;26:281-4.

17 Harries PG, MacKenzie FAF, Sheers G, Kemp JH, Oliver TP, Wright DS. Radiological survey of men exposed to asbestos in naval dockyards. Br J Ind Med 1972;29:274-9.

18 Felton JS. Radiographic search for asbestos-related disease in a naval shipyard. Ann NY Acad Sci 1979;330:341-52.

19 Berry G, Gilson JC, Holmes S, Lewinsohn HC, Roach SA. Asbestosis: a study of dose-response relationships in an asbestos textile factory. Br J Ind Med 1979;36:98-112.

20 Murphy RLH, Gaenster EA, Ferris BG, Fitzgerald M, Solliday N, Morrisey W. Diagnosis of "asbestosis": observations from a longitudinal survey of shipyard pipe coverers. Am J Med 1978;65:488-96.

21 Weiss W. Cigarette smoke, asbestos, and small irregular opacities. State of the art. Am Rev Respir Dis 1984;130:293-301.

22 Hughes JM, Weill H, Hammad YY. Mortality of workers employed in two asbestos cement plants. $\mathrm{Br} J$ Ind Med 1987;44:161-74.

23 Spurny KV, Pott F, Stober W, Opiela H, Schormann J, Weiss G. On the chemical changes of asbestos and man-made mineral fibres in biologic residence and in the environment. Part 1. Am Ind Hyg Assoc $J$ 1983;44:833-45.

24 Jaurand MC, Bignon J, Sebastien P, Goni J. Leaching of chrysotile asbestos in human lungs: correlation with in vitro studies using rabbit alveolar macrophages. Environ Research 1977;14:245-54.

25 Pooley FD. An examination of the fibrous mineral content of asbestos in lung tissue from Canadian chrysotile mining industry. Environ Research 1976;12:281-98.

26 Glyseth B, Mowe G, Wannag A. Fibre type and concentration in the lungs of workers in an asbestos cement factory. Br J Ind Med 1983;40:375-9.

27 Siracusa A, Cicioni C, Volpi R, et al. Lung function among asbestos cement factory workers: cross-sectional and longitudinal study. Am J Ind Med 1984;5:315-25.

28 Ohlson C-G, Bodin L, Rydman T, Hogstedt C. Ventilatory decrements in former asbestos cement workers: a four year follow up. Br J Ind Med 1985;42:612-6.

29 Gregor A, Parkes WR, du Bois R, Turner-Warwick M. Radiographic progression of asbestosis: a preliminary report. Ann NY Acad Sci 1979;330:147-56.

30 Barnes R. Progression of radiographic changes in asbestos workers and ex-workers. J Soc Occup Med 1986;36:9-12.

\section{Destruction of manuscripts}

From 1 July 1985 articles submitted for publication will not be returned. Authors whose papers are rejected will be advised of the decision and the manuscripts will be kept under security for three months to deal with any inquiries and then destroyed. 